\title{
INTERthesis
}

Revista

Internacional

Interdisciplinar INTERthesis

\section{DO HOMO SACER AO IUSTITIUM: DESLOCAMENTOS NA INTERPRETAÇÃO DO DIREITO ROMANO NA FILOSOFIA DE GIORGIO AGAMBEN}

Fabián Ludueña Romandini ${ }^{1}$

\begin{abstract}
Resumo
O artigo tem como objetivo apresentar os problemas teóricos e históricos ligados à compreensão do direito romano arcaico na filosofia de Giorgio Agamben. De um lado, se reconstrói o pano de fundo sobre o qual repousa o trabalho agambeniano sobre o direito romano, isto é, a tripla funcionalidade indo-europeia expressa na divisão sacer-sanctus-religiosus. Por outro lado, leva-se adiante uma análise das fontes acerca dos institutos do direito romano arcaico mais importantes estudados por Agamben: o homo sacer e o iustititum (este último diretamente relacionado à categoria de hostis publicus). Finalmente serão postuladas as possiveis razões dos deslocamentos operados por Agamben na utilização de ditas categorias em sua explicação do poder soberano em resposta às objeções de alguns filólogos especialistas em direito romano. Como resultado, logra-se uma melhor compreensão de suas estratégias metodológicas e de seu projeto filosófico.
\end{abstract}

Palavras-chave: Giorgio Agamben. Homo sacer. Iustitium. Hostis publicus. Poder soberano.

\section{INTRODUÇÃO}

A obra filosófica de Giorgio Agamben bem pode ser considerada como um tipo de arqueologia das instituições jurídicas e políticas do Ocidente que encontra alguns de seus modelos nos grandes propósitos de uma "antropologia da cultural ocidental". Nesse capítulo, nosso objeto será algumas de suas análises com respeito ao direito romano arcaico e, nesse campo específico, daquela instituição denominada homo sacer. Trata-se, então, de uma seleção metodológica e de um recorte de objeto. Nesse sentido, consideramos que textos posteriores de Agamben, como sua monumental arqueologia da teologia econômica cristã que tem seu início

\footnotetext{
${ }^{1}$ Doutor pela École des Hautes Études en Sciencies Sociales de Paris, França. Pesquisador do Consejo Nacional de Investigaciones Científicas y Técnicas (CONICET) e do Instituto de investigações "Gino Germani" da Faculdade de Ciências Sociais da Universidade de Buenos Aires, Buenos Aires, Argentina. Professor de pós-graduação na Faculdade de Ciências Sociais da Universidade de Buenos Aires, Buenos Aires, Argentina e professor associado de Filosofia na Universidade Argentina de la Empresa, Buenos Aires, Argentina. E-mail: fabianluduena@gmail.com
} 
em 2007 com seu livro O Reino e a Glória (AGAMBEN, 2011), não afetam, com respeito aos aspectos filológicos essenciais, a suas pesquisas prévias vinculadas ao direito romano arcaico.

A ambição teórica da genealogia do direito romano levada adiante por Giorgio Agamben só pode ser devidamente compreendida se é inscrita nessa linhagem daqueles que buscaram superar as dualidades entre história e estrutura, entre sincronia e diacronia, e que tentaram alcançar algo assim como a substância histórica mesma da política ocidental em seu alvorecer indo-europeu. Neste trabalho, nos concentraremos, como temos dito, em uma figura que definiu o horizonte e a essência mesma da indagação arqueológica levada adiante por Agamben: o homo sacer. Figura da "vida nua", da zoè em sua facticidade capturada pela esfera da soberania e casualmente emblema do cidadão das democracias modernas, o homo sacer é "o rendimento fundamental do poder soberano", o "elemento político original" e "limiar de articulação entre natureza e cultura" (AGAMBEN, 2002, p. 187). A figura do homo sacer, então, se encontra mais além, tanto do direito penal quanto do sacrifício religioso, ainda que ao mesmo tempo tenha sua origem em uma dupla exceção relacionada com ambas as esferas. A intenção de Agamben consiste então em identificar a "exclusão originária através da qual se constituiu a dimensão política" (AGAMBEN, 2002, p. 91)², isto é, o espaço em que se decidiu sobre a humanidade mesma do homem. Essa esfera não é ahistórica, como já se recriminou a Agamben, senão originária, quer dizer, completamente imbuída de historicidade enquanto Ur-phänomenon da política em seu aspecto soberano. Tampouco se trata, desde logo, de um essencialismo, senão de algo assim como a Entstehung da wirkliche Historie de que falava Friedrich Nietzsche. O espaço político do homem ocidental é, para Agamben, um espaço da excepcionalidade originária. Tentaremos aqui, contudo, explicitar em que sentido podemos falar de uma dimensão originária da exceção no homo sacer e, ao mesmo tempo, procuraremos mostrar a existência dentro da obra de Agamben de um deslocamento complementário da figura do homo sacer até o instituto do iustitium como paradigma da exceção. Referido deslocamento complementário, nem sempre adequadamente percebido pelos comentários especializados, deve ser explicado se se quiser compreender dita esfera originária que tenta mostrar o filósofo italiano.

\footnotetext{
${ }^{2}$ Sobre a distinção entre bíos y zoè, cf. CASTRO (2011, p. 18-19) e CASTRO (2012).
} 
Para isso, deveremos submeter a exame o pano de fundo sobre o qual emerge a figura mesma do homo sacer, isto é, a tripartição fundacional da civilização indoeuropeia exemplificada segundo as três categorias enunciadas pelo ius divinum romano (WISSOWA, 1902, p. 318-343): o sagrado (sacer), o santo (sanctus) e o religioso (religiosus). Esta hipótese da trifuncionalidade foi fortemente defendida por Georges Dumézil (1948, p. 174-176; 1974, p. 205) ao longo de sua obra. ${ }^{3}$

Um dos textos fundamentais sobre a tripartição indo-europeia do direito divino segundo o modelo romano é constituído pelas Institutas de Gaio:

\begin{abstract}
No comentário precedente, tratamos do direito das pessoas. Vejamos agora aquilo que concerne às coisas, que são consideradas como parte de nosso patrimônio ou bem como não pertencentes a ele. 2. É possível então estabelecer uma divisão principal das coisas em dois artigos: as coisas que são de direito divino e as coisas que são de direito humano. 3. São de direito divino, por exemplo, as coisas sagradas ou as coisas religiosas (diuini iuris sunt ueluti res sacrae et religiosae). 4. São sagradas (sacrae) as coisas que foram consagradas aos deuses superiores; as coisas religiosas (religiosae) são aquelas que foram abandonadas aos deuses manes. 5. Só se considera sagrado o solo que foi consagrado com a autorização do povo romano, por exemplo em virtude de uma lei ou de um senatusconsulto. 6 . Ao contrário, depende de nossa vontade o fato de fazer que algo se torne religioso, se enterramos um morto no lugar que nos pertence, sob a condição de que sua inumação nos incumba. 7. A maioria estima, sem embargo, que em um solo provincial, um lugar não se pode fazer religioso, posto que desse solo são proprietários ou bem o povo romano ou bem o Imperador, e supõe-se que nós só temos a posse ou o usufruto dele; notemos ao menos que inclusive se não é religioso, é tido como tal. 8. As coisas santas, como as muralhas ou as portas são igualmente de algum modo de direito divino (quodammodo diuini iuris sunt). 9. O que é de direito divino não se contabiliza entre os bens de quem quer que seja [...] (GAIUS, 1904, p. 122). ${ }^{4}$
\end{abstract}

Como se pode ver, Gaio estabelece no caso das coisas sagradas e religiosas uma classificação que obedece ao caráter biunívoco das divindades antigas. Assim, as coisas sagradas pertencem às divindades uranias e as religiosas às ctônicas.

\footnotetext{
${ }^{3}$ Para uma crítica da posição de Dumézil, cf. SOLAZZI, 1953, p. 104-133.

4 "Superiore commentario de iure personarum exposuimus; modo uideamus de rebus: quae uel in nostro patrimonio sunt uel extra nostrum patrimonium habentur. 2.2 Summa itaque rerum diuisio in duos articulos diducitur: nam aliae sunt diuini iuris, aliae humani. 2.3Diuini iuris sunt ueluti res sacrae et religiosae. 2.4Sacrae sunt, quae diis superis consecratae sunt; religiosae, quae diis Manibus relictae sunt. 2.5 Sed sacrum quidem hoc solum existimatur, quod <ex> auctoritate populi Romani consecratum est, ueluti lege de ea re lata aut senatus consulto facto. 2.6Religiosum uero nostra uoluntate facimus mortuum inferentes in locum nostrum, si modo eius mortui funus ad nos pertineat. 2.7Sed in prouinciali solo placet plerisque solum religiosum non fieri, quia in eo solo dominium populi Romani est uel Caesaris, nos autem possessionem tantum et usumfructum habere uidemur; utique tamen, etiamsi non sit religiosum, pro religioso habetur: item quod in prouinciis non ex auctoritate populi Romani consecratum est, proprie sacrum non est, tamen pro sacro habetur. 2.8Sanctae quoque res, uelut muri et portae, quodam modo diuini iuris sunt. 2.9Quod autem diuini iuris est, id nullius in bonis est..." (Cf. THOMAS, 2004, p. 40-73).
} 
Em ambos os casos, trata-se de formas de indisponibilidade dos bens consagrados garantidas pelo Estado e aplica-se a eles para sua definição o princípio superficies solo cedit, isto é, o solo predomina categoricamente sobre as superestruturas (BIONDI, 1938, p. 449-554).

Assim, sagrado é o solo onde se assenta a cidade de Roma e religioso é o solo onde se enterrou um morto. ${ }^{5}$ Por outro lado, em ambos os casos o texto comenta as formas de consagração: mediante uma lei ou um senatusconsulto, no caso das coisas sagradas, e a vontade de enterrar os mortos, no segundo. Estas duas categorias formam então um bloco lógico e argumentativo que fizeram os pesquisadores mais recentes sobre esta temática pensarem que as coisas santas estão longe de pertencer a uma tripartição fundamental, como pensava Dumézil, e que, em vez disso, esta é produto de uma construção jurídica posterior. ${ }^{6}$

De fato, podemos observar como, no caso das coisas santas, Gaio não disse que são estritamente de direito divino, mas que "de algum modo" podem ser consideradas como tais por meio de um tipo de analogia estrutural, com as coisas sagradas e religiosas posto que "santidade" é aqui também outra forma da indisponibilidade dos bens, ainda que estes últimos, apesar de encontrarem-se afetados de santidade, não pertençam à esfera da divindade. Nesse caso, nenhuma divindade preside sua consagração e o princípio de classificação jurídica da primazia do solo é infringido em função da declaração das muralhas ou portas como santas (SESTON, 1966, p. 1489-1498). A partir da inviolabilidade das muralhas como gesto fundacional da cidade, os jurisconsultos romanos puderam pensar a "santidade" como a inviolabilidade das leis como tais, ${ }^{7}$ sendo justamente a "sanção" o sentido da

\footnotetext{
${ }^{5}$ Sem embargo, como bem assinala Marciano, é necessário o consentimento do dono do terreno inclusive se este é retrospectivo - para poder verdadeiramente consagrar um solo como religioso. Cf. Dig. 1.8.6.4 (JUSTINIANO, 1899, vol. I, p. 227): "Religiosum autem locum unusquisque sua uoluntate facit, dum mortuum infert in locum suum. in commune autem sepulchrum etiam inuitis ceteris licet inferre. sed et in alienum locum concedente domino licet inferre: et licet postea ratum habuerit quam illatus 1.8.6.5 est mortuus, religiosus locus fit".

${ }^{6}$ É o caso das sugestivas análises de Solazzi que são retomadas e aprofundadas na erudita monografia de DE SOUZA, 2004, p. 42.

${ }^{7}$ Cf. Ulpiano, Dig, 1.8.9.3 (JUSTINIANO, 1899, vol. I, p. 227) : « Proprie dicimus sancta, quae neque sacra neque profana sunt, sed sanctione quadam confirmata: ut leges sanctae sunt, sanctione enim quadam sunt subnixae. quod enim sanctione quadam subnixum est, id sanctum est, etsi deo non sit consecratum: et interdum in san1.8.9.4ctionibus adicitur, ut qui ibi aliquid commisit, capite puniatur ». Note-se que Ulpiano estabelece que a "santidade " pode estabelecer-se sem necessidade da consagração a um deus.
} 
pena pela violação da santidade de uma lei, um castigo que bem podia consistir na morte. ${ }^{8}$

Se esta hipótese é correta, a construção jurídica posterior do santo como categoria de direito divino encontraria seu ponto máximo de articulação nas Instituciones de Justiniano, em que lemos:

As coisas que não pertencem a ninguém são as coisas sagradas, religiosas e santas; posto que aquilo que é de direito divino não pertence a ninguém. 8. As coisas sagradas são aquelas que foram solenemente consagradas a Deus pelos pontífices como os templos e os bens móveis solenemente consagrados ao culto divino. Proibimos por meio de nossa ordenação qualquer alienação ou compromisso, a menos que seja para a redenção dos cativos. Se alguém, por sua própria vontade, se dá como dever o considerar uma coisa como sagrada, ela não será por isso sagrada, mas profana. O lugar mesmo sobre o qual se constrói um templo permanece sagrado inclusive depois da destruição do edifício, como bem o assinalou Papiniano. 9. Cada um pode segundo sua própria vontade privada transformar um lugar em religioso, dando sepultura a um morto em seu terreno. Não se pode, sem o consentimento do co-proprietário, enterrar um morto em um lugar comum purus, mas se pode enterrar um morto em um sepulcro comum, inclusive apesar dos outros co-proprietários. Se o usufruto é separado da propriedade, o proprietário não pode enterrar um morto no terreno sujeito ao usufruto sem o consentimento do usufrutuário. Pode-se enterrar na terra alheia com o consentimento do dono e o lugar se transforma em religioso, inclusive se o dono muda de opinião depois do sepultamento. 10. As coisas santas, como os muros e as portas das cidades, são de algum modo de direito divino e por esta razão não pertencem a ninguém. O que faz que possamos chamar de santas as muralhas de uma cidade é que existe uma pena capital estabelecida pelas leis contra aqueles que as violem. Por isso chamamos sanção à parte das leis que tratam das penas impostas àqueles que agem contra a lei (JUSTINIANO, Institutiones, II, 1, 7-10: 7; 1889, vol. I, p. 31). ${ }^{9}$

\footnotetext{
${ }^{8}$ Neste sentido um dos maiores romanistas contemporâneos pode escrever que não é naquilo que proíbe que a lei é santa, mas na proibição, que existe, de violá-la como lei. (Cf. THOMAS, 1988, p. 61-84)

9 "Nullius autem sunt res sacrae et religiosae et sanctae: quod enim divini iuris est, id nullius in bonis est. 8. Sacra sunt, quae rite et per pontifices Deo consecrata sunt, veluti aedes sacrae et dona quae rite ad ministerium Dei dedicata sunt, quae etiam per nostrum constitutionem alienari et obligari prohibuimus, excepta causa redemptionis captivorum. si quis vero auctoritate sua quasi sacrum sibi constituerit, sacrum non est, sed profanum. locus autem, in quo sacrae aedes aedificatae sunt, etiam diruto aedificio, adhuc sacer manet, ut et Papinianus scripsit. 9. Religiosum locum unusquisque sua voluntate facit, dum mortuum infert in locum suum. in communem autem locum purum invito socio inferre non licet: in commune vero sepulcrum etiam invitis ceteris licet inferre. item si alienus usus fructus est, proprietarium placet, nisi consentiente usufructuario, locum religiosum non facere. in alienum locum, concedente domino, licet inferre: et licet postea ratum habuerit quam illatus est mortuus, tamen religiosus locus fit. 10. Sanctae quoque res, veluti muri et portae, quodammodo divini iuris sunt et ideo nullius in bonis sunt. ideo autem muros sanctos dicimus, quia poena capitis constituta sit in eos qui aliquid in muros deliquerint. ideo et legum eas partes quibus poenas constituimus adversus eos qui contra leges fecerint sanctiones vocamus".
} 
Neste texto, em que se apresenta a tripartição sacer-sanctus-religiosus como uma operação que pode ser lida como uma "manipulação de textos mais antigos" (DE SOUZA, 2004, p. 50), entre os quais se podem contar os de Gaio e Marciano, vemos operar um processo de cristianização do direito romano e de construção de uma lógica conjunta a respeito da inviolabilidade ou da indisponibilidade dos bens sob a forma de res in nullius bonis. Vemos também desaparecer aqui a menção às divindades antigas e a consagração se faz ao Deus cristão. Contudo, como assinalou De Souza, permanecem presentes algumas alusões a uma bipolaridade original do sacer-religiosus que haveria excluído, em um começo, o sanctus. O primeiro indício é constituído pela recuperação do quodammodo do texto de Gaio e, em segundo lugar, a menção de pares de opostos tanto para o sagrado como para o religioso, mas não para o santo. O profanum opõe-se ao sacer ${ }^{10}$ como o purus ao religiosus. ${ }^{11}$ Por outro lado, dentro da esfera do sanctus aparece não somente a muralha como também as leis.

Não obstante, tanto se pensamos o direito divino como tripartite (sacerreligiosus-sanctus), segundo a interpretação de Dumézil ou Bouché-Leclercq, como se o pensamos como bipartite (sacer-religiosus), segundo a hipótese defendida por Solazzi e De Souza, Giorgio Agamben segue neste ponto a hipótese de Émile Benveniste (1969, p. 187), que considera o sacer como a forma "mais precisa e específica do 'sagrado' ".12 Quer dizer, para Agamben, para além da hipótese

\footnotetext{
${ }^{10}$ Cf. Macrobio (1994, p. 167), que cita a célebre definição do jurista Trebacio Testa: "eo accedit quod Trebatius profanum id proprie dici ait quod ex religioso vel sacro in hominum usum proprietatemque conuersum est". Como se pode ver, Trebacio faz aqui alusão a uma divisão geral do direito entre o que é divino (sacer-religiosus) e o que pertence à esfera dos homens (profanum). Pois bem, dentro da esfera do divino, o sanctus não aparece mencionado, o que constitui para alguns autores (De Souza, por exemplo) uma prova suplementar do caráter originalmente dicotômico e não tripartite do direito divino.

${ }^{11}$ Esta oposição, que já se encontra enunciada em ULPIANO, Dig. XI, 7, 2, 4 (JUSTINIANO, 1889, vol. I, p. 662): "Purus autem locus dicitur, qui neque sacer neque sanctus est neque religiosus, sed ab omnibus huiusmodi nominibus uacare uidetur" e que poderia fazer pensar em uma tripartição original, constitui provavelmente uma glosa tardia (Solazzi, De Souza) ou bem uma reconstrução conceitual própria de Ulpiano, despertada ao pensar o regime da inviolabilidade (Cf. THOMAS, 1999, p. 110). No restante do Digesto, o purus sempre se opõe, de forma exclusiva, ao religiosus.

${ }^{12}$ Contudo, Agamben não segue Benveniste em sua consideração do sacer ao mesmo tempo como um valor positivo ("consagrado aos deuses") e um negativo ("maldito, que suscita horror"). As convincentes objeções de Agamben à teoria da " ambivalência do sagrado ", que retoma as teses já enunciadas e estudadas em detalhe por H.Fugier, encontram-se desenvolvidas em Agamaben (2002, p. 83-88). A primeira aparição da doutrina da ambivalência do sagrado encontra-se nas Lectures on the religion of the Semites de Robertson-Smith (1889) mas se encontra completamente ausente do Lateinisches etymologisches Wörterbuch de Walde (1910). A doutrina da ambivalência é sem embargo retomada no dicionário etimológico latino de Ernout-Meillet (1932), que recupera, nesse sentido, as doutrinas de Durkheim e Mauss.
} 
trifuncional - admissível ou não - de Dumézil, é pelo menos em alguns dos aspectos do sacer como tal que se joga uma das categorias fundamentais da política ocidental que se encontra, de longe, para além dos alcances do direito divino, ainda que este receba posteriormente, como vimos, este conceito entre suas categorias mais próprias. Desta forma, o sacer é o conceito fundante de toda a ordem jurídica.

Com vimos, o direito divino consagra a inviolabilidade e a indisponibilidade sob a forma do sacer-religiosus-sanctus. Pois bem, sob certa perspectiva, para Agamben, este é um uso tardio do sentido do sagrado. Antes, de um modo ao menos conceitual, se é que não também historicamente, se acha situada a aplicação do sacer não já aos bens corporais ou incorporais que se quer proteger, senão ao homem em sua primordial relação com a esfera do direito soberano. É o que deixa entrever a figura mesma do homo sacer.

Nesse sentido, é importante assinalar que Carl Schmitt (1950, p. 13) havia considerado o nomos originário de todo direito como uma confluência em que o assentamento no espaço (Ortung) faz visível uma estrutura jurídica fundante (Ordnung). A divisão do solo e do território dar-se-ia então, enquanto Landnahme (tomada de terra), o gesto jurídico fundamental que inaugura uma ordem política. ${ }^{13}$ Ainda que Schmitt não faça menção a ela, existe a raríssima obra de um antiquário, Heinrich Nissen, que havia proposto já quase um século antes uma teoria complementária a partir de uma análise do problema da sacralidade como esfera originária da política. $\mathrm{O}$ ato político original, segundo podemos deduzir da obra de Nissen (1869, p. 1-24), resulta do recorte e do reordenamento da cidade a partir da delimitação do espaço em função do sagrado (como âmbito religioso) e do profano

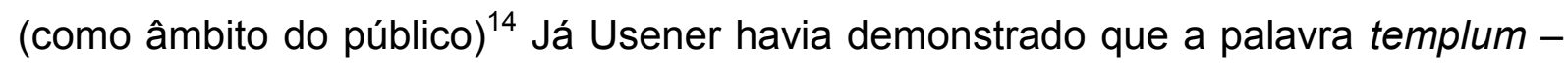
que em grego tem seu equivalente em témenos - deriva da raiz grega tem - que significa cortar e dividir. Segundo Usener (1878, p. 59-62), a noção mesma do tempo como tempus deriva desta concepção espacial; assim o tempo pode ser concebido como um espaço dividido e ordenado, uma delimitação particular do acontecer. A construção do templo seria então, sob esta perspectiva, o gesto político fundacional que separa a esfera do sagrado daquela da política profana e

\footnotetext{
${ }^{13}$ Schmitt toma esta categoria de Landnahme de Brunner (1902).

${ }^{14}$ Para uma crítica de certas posições extremas de Nissen a respeito do traçado dos templos, cf. FROTHINGHAM,1914, p. 302-320.
} 
cujo gesto residual pode-se observar no lituus dos áugures de Roma (LÍVIO, 1919, p. 66).

Apesar disso, seja se tomemos a via de Nissen e pensemos a política como corte, delimitação e ordenação da onipresença original do sagrado - e nesta concepção toda política se constrói como aquilo que o sagrado deixa fora ou expele de seu âmbito no mesmo gesto em que se constitui em esfera autônoma e separada - seja se sigamos a Schmitt e postulemos que é o ordenamento do espaço, antes como tomada da terra que como delimitação do sagrado, o que constitui a política (e ambas as posições não são necessariamente inconciliáveis), Agamben tenta confrontar-se com essas teorias ao afirmar que o homo sacer é a figura sobre a qual teve lugar o alvorecer da política ocidental como captura da vida nua, se e somente se pensarmos o homo sacer como o resultado de um entrecruzamento do sagrado e do profano como inclusão exclusiva.

Deste modo, o gesto soberano fundamental não consiste na delimitação do sagrado e do profano como esferas independentes, dentro dos grandes âmbitos da cidade, senão na produção de um espaço que não é propriamente religioso nem profano, sem deixar, portanto, de pertencer a ambas as esferas. Só assim, pode-se compreender a afirmação de Agamben, segundo a qual o espaço do homem sagrado é "mais íntimo que toda interioridade e mais externo que toda estraneidade", ou ainda que se trata do nomos que "condiciona todas as outras normas, a espacialização originária que torna possível e governa toda localização e toda territorialização" (AGAMBEN, 2002, p. 117), ou também a tese, segundo a qual esta estrutura política originária "tem seu lugar em uma zona que precede a distinção entre sacro e profano, entre religioso e jurídico" (AGAMBEN, 2002, p. 81).

Pois bem, o que é um homo sacer? Uma das definições mais precisas desta categoria encontramos no gramático Festus, quando este define a expressão sacer mons:

Sacer mons: Chamamos monte sagrado a um monte situado na outra margem do Aniene, um pouco além da terceira pedra militar, posto que o povo no momento de separar-se do senado e logo após a criação dos tribunos da plebe, estabelecidos para ajudá-lo, o consagrou a Júpiter no momento de retirar-se. Porém, dá-se o apelido de sacer ao homem que o povo julgou por um delito; não é permitido sacrificá-lo mas aquele que o mata não é condenado como homicida, posto que a primeira lei tribunícia estabelece esta disposição: "se alguém mata aquele que é sagrado por 
plebiscito, não será considerado homicida". Daí que em linguagem familiar se chame sacer a todo homem mau e impuro (FESTUS, 1997, p. 422-424) ${ }^{15}$

Os estudiosos não deixaram de manifestar sua perplexidade ante o paradoxo enunciado neste texto. De fato, o homo sacer, enquanto figura do direito penal arcaico, é aqui definido ao mesmo tempo como insacrificável e como suscetível de ser executado por qualquer um, sem que sobre o perpetrador recaia uma condenação por homicídio ou por sacrilégio. Alguns juristas como Mommsen (1899, p. 900-906) ou Strachan-Davidson (1912, p. 4-9) explicam a condenação à morte como resultado sacrificial de uma execução popular: a pessoa do culpável caía em poder dos deuses para ser-Ihes sacrificada, e era por isso, um homicídio não punível. Outros especialistas na história das religiões, como Kerényi (1995, p 76), ao contrário, sustentam que o caráter não-necessário do sacrifício se explica pelo fato de que o homo sacer já se encontra consagrado às divindades infernais pelo ato mesmo da sacratio e que consequentemente não tinha sentido algum voltar a repetir esse gesto de consagração com um novo sacrifício. Entretanto, nenhum estudioso pode até agora explicar ao mesmo tempo os dois traços característicos do homo sacer. insacrificabilidade e impunidade por matá-lo.

Para Agamben, por sua vez, a única possibilidade de dar conta satisfatoriamente da sacralidade do homo sacer é considerá-lo uma dupla exceção tanto ao ius divinum como ao ius humanum. Neste sentido, resulta sumamente importante recordar que os romanos possuíam vários modos de consagração à divindade. O regime da consecratio era aplicado às coisas; o sacrificium, aos animais (mas, também, aos homens no direito penal arcaico); e a sacratio, às pessoas sob a forma do homo sacer, sem que esse vocabulário seja desde logo unívoco. Pois bem, como é possível entender a figura do homo sacer como uma penalidade de dupla exceção? H. Fugier (1963, p. 242-243) estudou os tipos de delitos a que se aplicava a pena da sacratio. Entre eles devemos contar a violação da patria potestas quando o filho golpeia o pai: "se um filho golpeia o pai e, por outro lado, o pai chora, que o filho seja consagrado à divindade" ${ }^{16}$ ou quando um homem

\footnotetext{
15 "Sacer mons appellatur trans Anienem, paullo ultra tertium miliarium; quod eum plebes, cum secessisset a patribus, creatis tribunis plebis, qui sibi essent auxilio, discedentes lovi consecraverunt. At homo sacer is est, quem populus iudicavit ob maleficium; neque fas est eum immolari, sed, qui occidit, parricidi non damnatur; nam lege tribunicia prima cavetur, "si quis eum, qui eo plebei scito sacer sit, occiderit, parricida ne sit. Ex quo quivis homo malus atque inprobus sacer appellari solet."

${ }^{16}$ Festus (1997, p. 260): "Plorare, flere [inclamare] nunc significat, et cum praepositione inplorare, id R. Inter. Interdisc. INTERthesis, Florianópolis, v.10, n.2, p. 238-262, Jul./Dez. 2013
} 
repudia sua mulher: "quem ouse repudiar sua esposa será consagrado aos deuses do mundo inferior" ${ }^{\prime 17}$ Também a célebre instituição cardeal da ordem romana como foi o clientelismo, estava protegida pela sacratio de modo tal que,

\begin{abstract}
tanto para os patrões como para os clientes era ímpio e ilegal acusar-se mutuamente em pleitos, testemunhar ou jurar um contra o outro ou ainda contar-se entre os inimigos do outro; e quem quer que fosse acusado de fazer alguma dessas coisas seria culpado de alta traição segundo as leis de Rômulo e poderia legalmente ser morto por qualquer homem que desejasse o fazer, como se fosse uma vítima consagrada ao Júpiter das regiões infernais (HELICARNASO, 1937, p. 342). ${ }^{18}$
\end{abstract}

No âmbito da violação dos limites da ordem territorial urbana, que funda a ordem sócio-política, cabe citar a pena de sacratio para "aqueles que fazem pastar o gado secretamente de noite nas terras não maduras, destinadas ao cultivo" ${ }^{19}$, ou também para aqueles que transpassavam os limites dos campos que estavam sob a proteção do deus Término ${ }^{20}$ um gesto que implicava apagar os limites da cidade.

$\mathrm{Na}$ hora da consideração destes delitos, o gesto decisivo de Agamben é pensá-los não meramente como uma transgressão a uma norma do direito penal, mas, dada sua natureza fundante da ordem política, ditas infrações (atentado contra a patria potestas, clientelismo, alteração dos limites da cidade) devem ser vistas como "a relação política originária". Neste sentido, o homo sacer não tem nada de religioso e, em consequência, se trata de uma figura eminentemente jurídica, por meio da qual a vida é integrada no direito mediante uma inclusão exclusiva: "sacer esto não é uma fórmula de maldição religiosa, que sanciona o caráter unheimlich, isto é, simultaneamente augusto e abjeto, de algo: ela é, ao contrário, a formulação política original da imposição do vínculo soberano" (AGAMBEN, 2002, p. 93).

Isto implica considerar, diferentemente da posição de Nissen e de Schmitt, que não é tanto o assentamento e o traçado territorial quanto sua violação o que define a juridicidade penal constitutiva da cidade. O nómos originário funda-se então

est invocare: at apud antiquos plane inclamare. In regis Romuli et Tatii legibus: "si nurus . . , <nurus> sacra divis parentum estod." in Servi Tulli haec est: "si parentem puer verberit, ast olle plorassit paren<s>, puer divis parentum sacer esto." Aqui a enunciação da pena, sacer esto, não deve ser traduzida por 'seja sacrificado' mas por 'seja consagrado à divindade'.

${ }_{17}$ Plutarco (1914, p. 162), "ton d'apodómenon gunaîka thúesthai chroníois theoîs".

${ }^{18}$ Mas, também, na Lei das XII Tábuas, VIII (GIRARD, 1903, p. 20): "Patronus si clienti fraudem, sacer esto".

${ }^{19}$ Segundo (1950, p. 196): "frugem quidem aratro quaesitam furtim noctu pavisse ac secuisse puberi XII tabulis capital erat, suspensumque Cereri necari iubebant gravius quam in homicidio convictum, inpubem praetoris arbitratu verberari noxiamve duplionemve decerni."

${ }^{20}$ Festus (1997, p. 505): Terminus: "Numa Pompilius statuit, eum, qui terminum exarasset, et ipsum et boves sacros esse." 
não tanto no momento da demarcação de um território que é apropriado, mas no gesto com que "a vida humana, exposta a uma matabilidade incondicionada, vem a ser incluída na ordem política" (AGAMBEN, 2002, p. 93). E, segundo essa perspectiva, esta penalidade fundamental se encontra para além, tanto do direito divino como do direito humano, revelando-se como a esfera primordial sobre que se edificou a política ocidental.

Entretanto, vários anos depois da publicação de Homo sacer I, Giorgio Agamben retoma o problema da origem da ordem política, mas dessa vez deslocando da figura do homo sacer para a do iustitium o centro de gravidade. De fato, é esta instituição do direito público romano que se transforma, sem que os estudiosos desse aspecto da obra de Agamben a tenham enfatizado, com suficiente força, como pedra angular da demonstração do filósofo italiano em sua arqueologia do direito como estado de exceção.

Em primeiro lugar, devemos distinguir claramente a instituição romana da ditadura - seja esta comissária ou soberana ${ }^{21}$ - do iustitium como paradigma do estado de exceção apesar da tendência de certos estudiosos do passado em confundir essas figuras jurídicas. $O$ estado de exceção é concebido por Agamben justamente como um "estado" do direito que não pode nem deve ser identificado com uma magistratura ou um regime de governo determinado, como por exemplo a ditadura ou a democracia, mas que por sua própria natureza pode encontrar-se recobrindo todas as formas de organização política. Apesar disso, e dada a tenacidade com que usualmente se identifica o estado de exceção com a ditadura romana, é necessário delinear os contornos desta última instituição. ${ }^{22}$

A ditadura romana foi sempre o objeto de veneração por parte dos filósofos e escritores de política das mais diversas épocas. ${ }^{23}$ Isto se deve, sem dúvida, a que Roma atravessou sessenta e seis ditaduras sob a República e nenhum dos

\footnotetext{
${ }^{21}$ Retomamos aqui estes termos de Schmitt (1921, p XVIII-XIX). O livro de Schmitt não deixa de utilizar erroneamente o conceito de exceção ligado ao de ditadura.

${ }^{22}$ Existe um amplo debate entre os historiadores sobre as possíveis origens gregas da ditadura romana, em particular a partir dos testemunhos de Aristóteles (2005, p. 98) e de Helicarnaso (1937, p. 222) que cita explicitamente como antecedente desta instituição romana os aisymnetas gregos. Para este problema, cf. NICOLET, 1988, p. 37.

${ }^{23}$ Cf., por exemplo, Rousseau (1983, p. 226): "Então, tornando os costumes supérfluas muitas das precauções que foram necessárias em outros tempos, não se temia que um ditador abusasse de sua autoridade, nem que tentasse conservá-la além de seu mandato. Parecia, ao contrário, que um poder tão grande era muito pesado para quem dele se revestia, tanto se apressava em desfazer-se dele, como se ocupar o lugar das leis representasse um posto por demais penoso e perigoso."
} 
ditadores abusou das prerrogativas de seu cargo. Um ponto de controvérsia entre os especialistas sempre foi caracterizado por determinar a existência de um marco constitucional para esta magistratura. A partir da menção por parte de Tito Lívio de uma lex de dictatore creando, Mommsen (1877, p. 133-164) pode postular a existência de uma lei nesse sentido, apesar de que não existem outros documentos que avalizem essa afirmação.

A essa tradição opõem-se os pesquisadores que se apoiaram em um texto de Pomponius, que sugere algo assim como a criação espontânea de magistraturas segundo as necessidades políticas. ${ }^{24}$ André Magdelain provou, por outro lado, como todas as magistraturas romanas encontram seu fundamento em uma lei curial que se outorga depois da eleição. Assim cada magistrado recebe seu poder diretamente das cúrias e não de uma ordem normativa prévia que determine sua existência (MAGDELAIN, 1968). ${ }^{25}$

Desse modo, são os cônsules que, com o assentimento do Senado e, segundo a necessidade, podem criar uma nova magistratura, como, por exemplo, a ditadura.

Nesse sentido, existiam pelo menos duas classes de ditadura, ambas estabelecidas legalmente pelos cônsules: a rei gerendae causa, para a salvação da República, e a ditadura ordinária, para o cumprimento de certos ritos, a celebração de festas, o recrutamento excepcional de senadores, dentre outras possíveis tarefas. Se trata, então, neste último caso, de necessidades pontuais, que não põem em perigo a República como ordenamento político.

Muito se escreveu sobre os limites da ditadura, mas o certo é que nem a regra dos seis meses de exercício se cumpria - quase nunca -, nem tampouco os tradicionais meios de controle próprios dos tribunos como a intercessio, a provocatio ad populum ou a Lei Valeriae Horatiae do ano de 449 foram aplicados ao ditador, salvo tardiamente ${ }^{26}$ dado que, em princípio, estes direitos de controle só podem se exercer no pomerium, enquanto que o ditador não tinha limitações nem materiais

\footnotetext{
${ }^{24}$ Justiniano (1889, p. 202): "Populo deinde aucto cum crebra orerentur bella et quaedam acriora a finitimis infe<rr>entur, interdum re exigente placuit maioris potestatis magistratum constitui: itaque dictatores proditi sunt, a quibus nec prouocandi ius fuit et quibus etiam capitis animaduersio data est. hunc magistratum, quoniam summampotestatem habebat, non erat fas ultra sextum mensem retineri."

${ }^{25}$ Magdelain mostrou como, para a designação de um magistrado, eram seguidos três passos: a eleição, a investidura curial individual e a colação auspicial.

${ }^{26}$ Tampouco cabe sustentar que o ditador suspendia a validade da Lei Valeriae Horatiae. Pelo contrário, esta não Ihe concernia, já que a magistratura ditatorial havia sido criada anteriormente.
} 
nem territoriais para seu imperium. Por outro lado, Laurens Janssen demonstrou que quando o ditador deixa seu cargo, sempre utiliza nos textos o verbo abdicare que mostra a inexistência de um limite temporal ao exercício de um cargo - e nunca seu correlato abire, que implica uma deposição automática e não voluntária de uma magistratura (JANSSEN, 1960, p. 91-108). ${ }^{27}$

A partir destas características, pode-se ver que a ditadura não representa uma violação da ordem constitucional, posto que não existe proibição alguma a respeito desta instituição. Porém, tampouco se trata de uma magistratura estabelecida por meio de um estado de exceção já que nem o ditador nem o cônsul que o nomeia suspendem a validade da ordem normativa regular. Contudo, o ditador, sem suspender a ordem legal, pode se situar numa esfera em cujo interior encontra-se uma praxis que é independente do edifício jurídico. Este tipo de ação, própria do ditador, muitas vezes é passível de ser considerada como o protótipo do que, muitos séculos mais tarde, será chamado de a gestão de uma crise.

A ditadura não tem seu paradigma no estado de exceção, mas no da gestão desprovida de normas a priori, na mera administração da desordem e, por isso, essa magistratura é uma peça chave, não para a arqueologia do estado de exceção, mas para a genealogia da "governamentalidade" e da segurança fundada por Michel Foucault em seus cursos do Collège de France (FOUCAULT, 2005). É por isso que o instituto que, no direito romano corresponde ao Estado de Exceção, é o iustitium declarado por meio de um senatus consultum ultimum ( BARBAGALLO, 2010; DUPLA ANSUATEGUI, 1990). Este ponto, nem sempre claramente assinalado pelo pesquisadores modernos, havia sido perfeitamente compreendido por Maquiavel, que em seus Discursos evocou a diferença entre a ditadura e a medida conhecida como senatus consultum ultimum:

\footnotetext{
Vale notar, aliás, que nos últimos tempos da república, os romanos, em vez de instituir um ditador, atribuíam poderes ditatoriais ao próprio cônsul, servindo-se da fórmula: "videat consul ne respublica quid detrimenti capiat" (MAQUIAVEL, 1979, p. 115).
}

Nesse sentido, além do iustitium, existiam outras medidas da exceção, em Roma, conhecidas como saga sumere, evocatio, crimen maiestatis e a declaração de hostis publicus. Agora, vejamos por que é possível dizer que o iustitium é o

${ }^{27}$ Cf. também o fundamental estudo de SAINT-BONNET (2001), que distingue, com numerosas fontes, as diferenças entre ditadura e estado de exceção. 
paradigma do estado de exceção? No mais agudo estudo que existe sobre esta questão, escrito por Adolf Nissen, podemos ler:

Quando o direito não estava mais em condições de assumir sua tarefa suprema, a de garantir o bem comum, abandonava-se o direito por medidas adequadas à situação e, assim como, em caso de necessidade, os magistrados eram liberados das obrigações da lei por meio de um senatusconsulto, em caso extremo também o direito era posto de lado. Quando se tornava incômodo, em vez de ser transgredido, era afastado, suspenso por meio de um iustitium (NISSEN, 1877, p. 99).

Como é possível notar, o iustitium é declarado por meio de um senatusconsulto que pressupõe a presença de um tumultus. Pois bem, todas estas categorias "não pertencem à esfera do direito penal, mas à do direito constitucional" e marcam o ponto no qual o direito é suspenso frente à guerra civil. Cícero recorda essa instituição, que uma vez declarada autorizava qualquer cidadão a dar morte ao insurreto ante a caducidade do direito, quando escreve a propósito da conspiração de Catilina: "Faz já tempo, Catilina, que terias de haver sido condenado à morte pela ordem de um cônsul, e que essa destruição, que tu desde há muito maquinas contra nós, teria que se haver voltado contra ti” (CÍCERO, 1906, p. 4). ${ }^{28}$

Imediatamente depois, Cícero recorda em seu discurso, as ocasiões em que se havia utilizado o instituto:

Em certa ocasião o Senado decretou que o cônsul Lucio Opimio tomasse
medidas para que a república não sofresse qualquer dano. Não passou uma
só noite. Gayo Graco, de pai, avô e antepassados famosíssimos, foi
justiçado por certas suspeitas de sedição; o ex-cônsul Marco Fulvio foi
morto, junto com seus filhos. Por um decreto senatorial, confiou-se a
república aos cônsules Gaio Mario e Lucio Valeiro. Por acaso se adiou por
um só dia ao tribuno da plebe Lucio Saturnino e ao pretor Gaio Servilio a
pena de morte imposta pela república? (CíCERO, 1906, p. 4$)^{29}$

Em todos estes casos, a consequência da declaração do iustitium por meio de um senatus-consulto trazia consigo a declaração do rebelde como hostis. Desse modo, o inimigo público era "radicalmente privado de todo estatuto jurídico e podia, portanto, em qualquer momento, ser destituído da posse de seus bens e condenado à morte" (AGAMBEN, 2004, p. 123). Para Agamben (2004, p. 59-63), esse instituto

\footnotetext{
28 "Ad mortem te, Catilina, duci iussu consulis iam pridem oportebat, in te conferri pestem quam tu in nos omnis iam diu machinaris."

29 "Decrevit quondam senatus uti L. Opimius consul videret ne quid res publica detrimenti caperet: nox nulla intercessit: interfectus est propter quasdam seditionum suspiciones C. Gracchus, clarissimo patre, avo, maioribus, occisus est cum liberis M. Fulvius consularis. Simili senatus consulto C. Mario et $L$. Valerio consulibus est permissa res publica: num unum diem postea L. Saturninum tribunum plebis et $C$. Servilium praetorem mors ac rei publicae poena remorata est?"
} 
judicial não se limita apenas a explicar um fenômeno histórico, mas também resulta ser paradigmático do proceder intrínseco à estrutura de todo o direito ocidental, que não pode realizar-se na praxis sem inexecutar-se ao mesmo tempo.

Nesse sentido, o iustitium não é equiparável à ditadura, posto que esta funciona - ainda que com todas as especificidades do caso - dentro do esquema do direito, enquanto o primeiro instituto pressupõe o caráter absoluto da anomia e uma suspensão da ordem jurídica in toto.

\section{CONCLUSÃO}

Em 1996, pouco depois da publicação do primeiro volume da indagação sobre o direito ocidental, os romanistas reagiram ante a análise agambeniana do homo sacer. O centro da atenção dos romanistas não se refere ao funcionamento da pena de sacralidade no direito arcaico. Suas objeções estão dirigidas ao coração do projeto de Agamben, posto que, segundo alguns romanistas, nosso filósofo escolheria uma figura imprópria para a exemplificação da exceção soberana.

Além do caso extremo de alguns especialistas, que tem estimado como muito fragmentária a historicidade do homo sacer (KIESOW, 2002, p. 62), há estudiosos que consideram essa última figura inadequada para dar conta da excepcionalidade soberana, dado que, se trata de um castigo do direto penal instituído por uma cadeia popular que se realizaria fora dos marcos do poder soberano. Os romanistas recordarão, então, que o poder soberano no direito romano arcaico castigava por meio do sacrificium, ou seja, uma pena capital de tipo ritual. Nesse sentido, o homo sacer fica excluído dos meios da penalização soberana por se tratar de um assassinato consentido aos privati em forma não ritual, mas somente a esses e não aos magistratus legitimi (FIORI, 1996, p. 443).

Consequentemente, a única figura que realmente representa a exceção soberana seria o hostis rei publicae que é privado de todo direito e assassinato pelo poder soberano, mediante a declaração de um iustitium com seu correspondente senatus consultum ultimum. Com efeito, é possível sinalizar notáveis analogias entre o homo sacer e o hostis rei publicae, entre as quais cabe mencionar o fato de que, se o hostis publicus estava em mãos do senado, comportava sua imediata execução. Contudo, se não era possível ter com o culpado imediatamente, o 
senatus consultum ultimum consentia, ao menos a partir do ano 88 a.C., que qualquer cidadão pudesse assassiná-lo sem que isso resultasse ser um homicídio. Como corolário dessas características próprias do instituto, a declaração de hostis publicus também podia ser emitida sem que fosse necessária a declaração de um estado de exceção, ainda se a ação pudesse ser concebida como um bellum iustum.

Certamente, é possivel conceber a declaração de hostis publicus como uma forma de "dessacralização" da consecratio capitis própria da sacratio originária. Nesse sentido, estaríamos frente ao mesmo processo que conduziu da consecratio bonorum à publicatio (SALERNO, 1990). Cabe perguntar-se, então, pelo motivo segundo o qual o próprio Agamben não sinalizou explicitamente as simetrias contundentes que existem entre ambos institutos. Dito de outro modo, qual a razão de Agamben deslocar sua atenção da figura do homo sacer, como paradigma da exceção soberana (Homo sacer I), à do iustitium, como forma última da anomia fundamental do direito (Estado de exceção)?

Com efeito, alguns romanistas, como Fiori (1996, p. 522), têm levantado a objeção, segundo a qual somente o hostis rei publicae corresponde a uma punição própria do poder soberano (admitindo que este último conceito seja válido para a realidade romana), enquanto que a sacratio própria do homo sacer pertencia a uma penalidade de tipo privado, a qual estavam isentos de praticar os magistrados públicos, aos quais estava reservada, em tempos arcaicos, a pena soberana unicamente sob a forma do supplicium.

Esse deslocamento significa uma concessão aos romanistas e uma eventual correção não explicitada, por parte de Agamben, de sua própria tese a respeito da qual seria a forma mais própria da precipitação da "vida nua" sob o poder soberano? Dito de outro modo, a mudança de acento no período transcorrido entre Homo sacer I (1995) e Estado de exceção (2003) comporta também um reconhecimento de que, na verdade, a figura mais apropriada da captura soberana da "vida nua" corresponderia ao hostis publicus e não ao homo sacer? Não podemos saber se Agamben tomou em conta as objeções dos romanistas, dada a ausência explícita em sua obra de menções quanto a um ou outro sentido. Não obstante, é possível pensar que esse deslocamento significa uma mutação da escala de análise e um efeito de complementariedade na investigação e, de nenhum modo, uma mudança de perspectiva. Em outros termos, o projeto filosófico de Agamben não seria 
afetado. Ao contrário, seria enriquecido com o tratamento de duas figuras solidárias a um mesmo paradigma.

Desde sempre, para os romanistas, o homo sacer tratou-se de uma figura do direito penal popular e o iustitium de uma figura extrema do direito constitucional. Não obstante, a tese de Agamben consiste em pensar ambos os institutos como exceções comparáveis com respeito a ambos os tipos de direito e, definitivamente, como formas jurídicas que respondem a uma lógica rigorosa e idêntica. Do mesmo modo, a sacralidade do homo sacer é uma dupla exceção, tanto em relação ao direito divino quanto ao humano e o iustitium, é o estado kenomático de um direito suspenso. Pouco importa, nesse sentido, se o poder soberano que castiga o homo sacer é um magistrado ou um povo mediante uma imolação não ritualizada: o gesto soberano aparece em qualquer um dos casos no tratamento da transgressão como exceção.

No primeiro caso, o homo sacer, trata-se de uma excepcionalidade que funda a ordem jurídica excluindo a vida do transgressor por meio de sua morte, ao mesmo tempo que a inclui na decisão soberana de matar. Assim, como gesto fundador de todo a ordem política é necessariamente anterior à instituição do hostis rei publicae. Por outro lado, o iustitium não responde tanto à origem do poder soberano - ainda que sempre o recorde em sua anomia fundamental -, mas ao modo de exercício que este possui na forma de um corpo normativo desenvolvido.

De fato, o homo sacer leva consigo uma ação de exceção para poder ser executado e dita ação retoma a tradição de seu surgimento, quando dita prática esteve situada originalmente fora dos direitos existentes (divino e humano) para fundar uma ordem jurídico-política sobre a precipitação da vida nua. O iustitium, por seu lado, salvo alguns casos especiais, supõe uma dissolução da ordem normativa para castigar o inimigo público e, portanto, é solidário com a excepcionalidade como motor oculto da maquinaria jurídica. De acordo com essa perspectiva, poderíamos considerar o homo sacer e o iustitium como os dois polos de intensidade de um mesmo continuum da exceção, como duas esferas históricas e conceitualmente distintas, mas complementárias e compatíveis sobre as quais se funda o poder soberano e a ordem política.

Um esclarecimento ulterior, nesse sentido, provém de uma obra recente de Agamben dedicada à instituição do juramento. Nesse texto, mais uma vez, Agamben 
(2008, p. 40-41) volta sobre a sacratio, dessa vez, em sua estreita conexão com o sacramentum e, mesmo que não se trate da relação originária com a esfera soberana, podemos constatar que, implicitamente, Agamben mantém sua postura primigênia no tocante à questão concernente à relação, afirmada por nosso filósofo, entre sacratio e soberania. Com efeito, escreve Agamben:

A interpretação da sacertas como prestação originária do poder por meio da produção de uma vida nua assassinável e insacrivicável deve ser integrada no sentido de que, ainda antes de ser sacramento do poder, o julgamento é consagração do vivente à palavra através da palavra (AGAMBEN, 2008, p. 90).

Dessa forma, Agamben não só mantém sua validade do instituto da sacertas, como, também, a mesma é aproximada a seu estudo acerca do sacramento da linguagem. Precisamente, nessa pesquisa, Agamben questiona radicalmente as noções utilizadas classicamente pelos historiadores e linguistas insistindo na necessidade, já expressa em Homo sacer I, de liberar-se da oposições rígidas entre sagrado e profano, ou entre direito e pré-direito. A partir dessa perspectiva, é plausível, então, sustentar a hipótese segundo a qual uma adequada compreensão do instituto do homo sacer comporta também, necessariamente, uma posta em suspenso da oposição entre público e privado (uma dicotomia amplamente utilizada pelos romanistas, mas incompatível com as perspectivas no âmbito das análises propostas por Agamben). Dessa forma, o público e o privado também poderiam ser entendidos como os dois polos extremos de um mesmo campo de intensidades.

Se isso é certo, então, que a sacertas dependa, para sua execução, da determinação dos privados ou de um magistrado específico, é um debate de detalhe que não deixa de carecer de interesse, mas que não afeta o essencial. Uma vez dissolvida a concepção tradicional da dicotomia entre público e privado, como esferas independentes e sem conexão, a sacralidade do homo sacer aparece com seu verdadeiro rosto: nesse ponto, pouco importa quem execute o vivente declarado sacer, pois quem o faça, nesse preciso instante, passa a exercer a função soberana de dar à morte. Essa posição já se encontrava delineada em Homo sacer I. É o modo segundo o qual devem ser entendidas algumas proposições do filósofo italiano, como quando sustenta que "soberana é a esfera na qual se pode matar sem cometer homicídio e sem celebrar um sacrifício, e sacra, isto é, matável e insacrificável, é a vida que foi capturada nesta esfera" (AGAMBEN, 2002, p. 91), ou, 
mais adiante, quando estabelece que "homo sacer é aquele em relação ao qual todos os homens agem como soberanos" (AGAMBEN, 2002, p. 92).

Nesse sentido, Agamben não se concentra sobre a magistratura como soberania constituída, nem sobre a comunidade como ofício punitivo privado. Sua intenção consiste em captar, em qualquer homem, o gesto que permite o nascimento da "função soberana" a qual, anterior a toda divisão entre público e privado, é expressa de modo privilegiado na forma da morte do sacrificável não punível. Assim, o nascimento da biopolítica consiste, plenamente, em pôr à disposição a vida humana para sua morte. Ato por meio do qual o direito soberano começa a ser instaurado antes como transgressão da vida do que como geração de um espaço territorial e normativo unitário. 


\title{
FROM THE HOMO SACER TO THE IUSTITIUM: DISPLACEMENTS IN THE INTERPRETATION OF ROMAN LAW IN GIORGIO AGAMBEN'S PHILOSOPHY
}

\begin{abstract}
This article aims to introduce the theoretical and historical problems related to the comprehension of archaic Roman Law in Giorgio Agamben's philosophy. In the background that Agamben has based his work on Roman Law is reconstructed, that is to say, the Indo-European trifunctional hypothesis expressed in the sacer-sanctusreligiosus division. On the other hand, a source analysis is carried out about two of the most important institutes of archaic Roman Law studied by Agamben: the homo sacer and the iustititum (the latter directly related to the category of hostis publicus). Finally, some possible reasons are advanced concerning the displacements made by Agamben when using these categories in his explanation of sovereign power as a response to some objections coming from philologists specialized in Roman Law. As a result, a better understanding of his methodological strategies and his overall philosophical project is achieved.
\end{abstract}

Keywords: Giorgio Agamben. Homo sacer. lustitium. Hostis publicum. Sovereign power.

Del homo sacer al iustitium: desplazamientos en la interpretación del derecho romano en la filosofía de giorgio agamben

\section{Resumen}

El artículo tiene como objetivo presentar los problemas teóricos e históricos ligados a la comprensión del derecho romano arcaico en la filosofía de Giorgio Agamben. Por un lado, se reconstruye el trasfondo sobre el cual se asienta el trabajo agambeniano sobre el derecho romano, es decir, la trifuncionalidad indoeuropea expresada en la división sacer-sanctus-religiosus. Por otro lado, se lleva adelante un análisis de fuentes acerca de los dos institutos del derecho romano arcaico más importantes estudiados por Agamben: el homo sacer y el iustitium (este último directamente relacionado con la categoría de hostis publicus). Finalmente se postulan las posibles razones de los desplazamientos operados por Agamben en la utilización de dichas categorías en su explicación del poder soberano en respuesta a las objeciones de algunos filólogos especialistas en derecho romano. Como resultado, se logra un mejor entendimiento de sus estrategias metodológicas y de su proyecto filosófico.

Palabras clave: Giorgio Agamben. Homo sacer. Iustitium. Hostis publicus. Poder soberano. 


\section{REFERÊNCIAS}

AGAMBEN, Giorgio. Homo sacer. O poder soberano e a vida nua I. Henrique Burigo (Trad.). Belo Horizonte: Editora UFMG, 2002.

AGAMBEN, Giorgio. Estado de Exceção. Homo Sacer II, 1. São Paulo: Boitempo Editorial, 2004.

AGAMBEN, Giorgio. O Reino e a Glória. Selvino Assmann (Trad.). São Paulo: Boitempo, 2011.

AGAMBEN, Giorgio. II sacramento del linguaggio. Archeologia del giuramento (Homo sacer II, 3). Bari: Laterza, 2008.

ARISTÓTELES. Política. Juán Marías y María Araujo (Eds). Madrid: Centro de Estudios Políticos y Constitucionales, 2005.

BARBAGALLO, Corrado. Una misura eccezionale dei romani. Senatus-Consultum Ultimum. Montana: Kessinger Publishing, 2010.

BENVENISTE, Émile. Le vocabulaire des institutions indo-européennes. Paris: Éditions de Minuit, 1969.

BIONDI, Biondo. La categoria romana delle "servitutes". Milán: Società editrice Vita e pensiero, 1938.

BRUNNER, Heinrich. Deutsche Rechtgeschichte. Berlin: Duncker \& Humblot, 1902.

CASTRO, Edgardo. Acerca da (Não) distinção entre Bíos e Zoé. Interthesis, v. 9, n. 2, p. 51-61. 2012

CASTRO, Edgardo. Lecturas foucaulteanas. Una historia conceptual de la biopolítica. La Plata: Unipe Editorial Universitaria, 2011.

CÍCERO. In Catilinam orationes quattuor. Aloisius Kornitzer (Ed.). Vindobonae: C. Gerold filii, 1906. 
DIONISIO DE HELICARNASO. Antiquitates romanae (The Roman Antiquities). Edward Spelman (Ed.). London: Massachusetts: Harvard University Press, 1937.

DUMEZIL, Georges. La religion romaine archaïque avec un appendice sur la religion des Étrusques. Paris: Payot, 1974.

DUMEZIL, Georges. Júpiter, Mars, Quirinus IV. Explication de textes indiens et latins, Bibliothèque de l'Ecole des Hautes Etudes - Section des Sciences Religieuses, v. 42. Paris: Presses Universitaires de France, 1948.

DUPLA ANSUATEGUI, A. Videant Consules. Las medidas de excepción en la crisis de la República romana. Zaragoza: Universidad de Zaragoza, 1990.

FESTUS, Sextus Pompeius. De verborum significatu quae supersunt. Cum Pauli Epitome. Edición de Wallace M. Lindsay. Stuttgart - Leipzig: 1997.

FIORI, Roberto. Homo sacer. Dinamica político-costituzionale di una sanzione giuridico-religiosa. Napoli: Jovene Editore, 1996.

FROTHINGHAM, Arthur. Circular Templum and Mundus. Was the Templum Only Rectangular? American Journal of Archaeology, v. 18, n. 3, july/sept, p. 302-320. 1914.

FOUCAULT, Michel. Sécurité, Territoire, Population. Cours au Collège de France 1977-1978. Paris: Gallimard-Seuil, 2005.

FUGIER, Hugette. Recherches sur l'expression du sacré dans la langue latine. Strasbourg: Presses Universitaires de Strasbourg, 1963.

GAIUS. Institutiones. Edward Poste (ed). Oxford: Clarendon Press, 1904.

GIRARD, Paul Frédéric. Textes de Droit Romain publiés et annotés. Paris: Arthur Rousseau, 1903.

JANSSEN, Laurens Franciscus. Abdicatio. Nieuve onderzoekingen over de dictatuur. Utrecht: Kemink \& Zoon, 1960. 
JUSTINIANO. Corpus luris Civilis. Ildefonso García del Corral (Ed.). Barcelona: Jaime Molinas Editor, 1889.

KERENYI, Karl. Antike Religion. Stuttgart: Klett-Cotta, 1995.

KIESOW, Rainer Maria. lus sacrum. Giorgio Agamben und das nakte Recht. Rechtsgeschichte I. Heidelberg, 2002, p. 56-70.

LIVIUS TITUS. Ab urbe condita. Foster B.O. (Ed.) v. 13. London - Massachusetts: Harvard University Press, 1919.

MACROBIUS. Saturnalia. James Willis (Ed.). v.2. Stuttgart - Leipzig: Teubner, 1994.

MAGDELAIN, André. Recherches sur l'imperium. La loi curiate et les auspices d'investiture. París: Presses Universitaires de France,1968.

MAQUIAVEL. Comentários sobre a Primeira Década de Tito Lívio (Discorsi). Sérgio Bath (Trad.). Brasília: Universidade de Brasília, 1979.

MOMMSEN, Theodor. Römische Strafrecht. Leipzig: Duncker \& Humblot, 1899.

MOMMSEN, Theorodor. Römisches Staatsrecht. 3 Bd. Leipzig: Hirzel Verlag, 1877.

NICOLET, Claude. Dictateurs romains, stratégoi autokratores et généraux carthaginois. In: HINARD, François (Org.). Dictatures. París : De Broccard, 1988. p. $27-47$.

NISSEN, Adof. Das lustitium. Eine Studie aus der römischen Rechtsgeschichte. Leipzig: Gebhardt, 1877.

NISSEN, Heinrich. Das Templum: antiquarische Untersuchungen. Berlin: Weidmannsche Buchhandlung, 1869.

PLÍNIO SEGUNDO. Naturalis Historia (Natural History). H. Rackham (Ed.). v. 10. London - Massachusetts: Harvard University Press, 1950.

PLUTARCO. Lives. Bernadotte Perrin (Ed.). London - Massachusetts: Harvard University Press, 1914.

R. Inter. Interdisc. INTERthesis, Florianópolis, v.10, n.2, p. 238-262, Jul./Dez. 2013 
RASCH, William. From Sovereign Ban to Banning Sovereignty. In: CALARCO, Matthew; DE CAROLI, Steven (Eds.). Giorgio Agamben. Sovereignty and Life. Standford: Standford University Press, 2007, p. 92-108.

ROUSSEAU, Jean Jacques. Do Contrato Social ou Princípios do Direito Político. Lourdes Santos Machado (Trad.). São Paulo: Abril Cultural, 1983.

SAINT-BONNET, François. L'État d'exception. Paris: Presses Universitaires de France, 2001.

SALERNO, Francesco. Dalla "conscratio" alla "publicatio bonorum". Forme giuridiche e uso politico dalle origini a Cesare. Napole: Jovene Editore, 1990.

SCHMITT, Carl. Der nomos der Erde im Völkrecht des jus publicum europaeum. Berlin: Duncker \& Humblot, 1950.

SCHMITT, Carl. Die Diktatur. Von den Anfängen des modernen Souveränitätsgedankens bis zum proletarischen Klassenkampf. Berlin: Duncker \& Humblot 1994.

SESTON, William. Les murs, les portes et les tours des enceintes urbaines et le problème des res sanctae en droit romain. In : CHEVALIER, Raymond (Ed.).

Mélanges d'archéologie et d'histoire offerts à André Piganiol, v. 3. Paris: École Pratique des Hautes Études,1966.

SOLAZZI, Siro. "Quodam modo" nelle istituzioni di Gaio. Studia et documenta historiae et iuris, 19, 1953, p. 104-133.

SOUZA, Manuel de. La question de la tripartition des catégories du droit divin dans l'Antiquité romaine. Saint-Étienne: Publications de l'Université de SaintÉtienne, 2004.

STRACHAN-DAVIDSON, James Leigh. Problems of the Roman Criminal Law. v. 2. Oxford: Clarendon Press, 1912.

THOMAS, Yan. Res religiosae: on the categories of religion and commerce. In: POTTAGE, A.; MUNDY, M. (Eds.), Law, Anthropology, and the Constitution of the Socal Making Persons and Things. Cambridge, 2004, p. 40-73. 
THOMAS, Yan. Corpus aut ossa aut cineres. La chose religieuse et le commerce. Mircrologus, VII, 1999, p. 73-112.

THOMAS, Yan. Sanctio. Les défenses de la loi. L'écrit du temps, n. 19. Paris, 1988, p. 61-84.

USENER, Hermann. Templum.117. Fleckeisens Jahrbüch für Philologie, 1878, p. 59-62.

WISSOWA, Georg. Religion und Kultus der Römer. München: C.H. Beck'sche Verlagsbuchhandlung, 1902. 